\title{
sciendo
}

10.2478/msd-2019-0006

\section{OPTIMAL OPERATION AND SCHEDULING OF PARALLEL MACHINES IN JOB- SHOP ENVIRONMENTS}

\author{
Maurizio, FACCIO ${ }^{\text {a }}$, Mojtaba, NEDAEI ${ }^{b}$ \\ Department of Management and Engineering, Vicenza, Italy. \\ Email addresses: (a): maurizio.faccio@unipd.it; (b): mojtaba.nedaei@studenti.unipd.it
}

\begin{abstract}
Scheduling of machines together with the optimization of the energy consumption (EC) play a crucial role in every manufacturing system. The current paper aims to present a multi-objective optimization approach for planning and scheduling of a manufacturing system in a job-shop environment. First, an inclusive review and comparison of the latest advancements in this field was performed. Then, a manufacturing system in a job-shop environment, which consists of six designed machines with zero buffer capacity, and 53 jobs, was simulated. Four heuristics for the purpose of sequencing are adopted during the analysis process. A comparison of the optimum results suggested the most efficient values for the EC, make-span, and tardiness. The EC variations and processing time of the machines were studied under sequencing rules to let the designers exploring more efficient solutions, and planning strategies towards enhancing the performance and reliability of studied machines. Next step of this study was to estimate the optimum completion time of each process in the considered manufacturing system and with consideration of the proposed scheduling methods.
\end{abstract}

KEY-WORDS: Scheduling, flow shops, make-span, sequencing, optimization, energy utilization.

\section{INTRODUCTION}

Over the past decade, the manufacturing firms have confronted a series of indispensable challenges worldwide. The economic trend, increasing price of the energy, the progress of shorter product life cycles, and enhancing the customer demand diversity are just a few examples of such challenges. The enormous, as well as the devastating environmental challenges of the global warming, and climate change, quick depletion of the conventional sources of power such as oil, gas and coal, as well as the biodiversity decline are all other difficulties, which are typically encountered by the legislators, and stakeholders around the globe. On this account, the aim of many modern manufacturing firms, is to reduce the EC, both to save cost, and to make progress towards more environmentally friendly energy systems.

The research in the area of manufacturing has primarily concentrated on the optimization of the machines EC, as well as the product levels. As a matter of fact, from a manufacturing viewpoint, improving the objectives of the production scheduling is a feasible, and efficient approach for manufacturing firms to lower the EC without any machine or product redesign. During the scheduling, processes are typically adjusted in accordance with the functions of different components. Scheduling also plays a crucial role in the manufacturing process of the machines, and equipment. It involves arrangements, controlling, and optimizing the work schedules as well as the workloads in a production or manufacturing process. The main purpose of this process would be to allocate plant and machinery resources, plan human resources, plan production processes and purchasing the materials.

\subsection{Literature review and research background}

The preliminary investigations in the field of scheduling may trace back to 1960s [1]. In a recent time, a considerable amount of attention and interest has been dedicated towards the production-scheduling problems, which take into account energy efficiency improvement, cost-saving and environmentally friendly system modes. Most of these research works have primarily dealt with development of different mathematical models to solve specified scheduling problems. In the following, a brief review of the conducted studies has been outlined:

A flow-shop problem was first studied by Johnson [2] concerning two machines. Ever since, several researchers have generalized the Johnson's rule to ' $\mathrm{m}$ ' machine flow shop scheduling heuristics. Mouzon et al. [3] noticed that in several manufacturing and production firms, the operating status of non-bottleneck machines, is invariably considered to be idle. On this account, an approach with regard to machine scheduling, was employed to analyze the required time and electricity consumption data for a series of specified machines. Fu et al. [4] presented a novel flow shop scheduling model with consideration of multiple objectives, uncertainty, deteriorating and learning effect in an in an industry 4.0-based manufacturing environment. Wang et al. [5] was concentrated on the modelling of a sequence, which was dependent upon the two machine flow shops to supply a low-consumption of the energy. Fang et al. [6] developed a novel structure based on the mixed integer linear programming to perform the scheduling and design of a flow shop problem, which took into account the peak total power consumption, the EC, and the associated carbon footprints in addition to the cycle time. Karasakal and Koksalan [7], considered two single machine problems in 
order to minimize the flow time, the number of tardy jobs, and the maximum earliness, respectively. They applied a simulated annealing (SA) method to generate an approximately efficient solution for the investigated problem. Xu et al. [8] studied two-machine flow shop scheduling with an availability constraint using mixed integer linear by proposing seven mixed integer programming formulations. In another research, Wang et al. [9], proposed an optimal scheduling technique to select appropriate batch and sequence policies to improve the paint quality and decrease repaints, thereby reducing energy and material consumption in an automotive paint shop. Guerrero et al. [10] evaluated the impact of the production system design on EC by using a case study example at an automotive paint shop. Yan et al. [11] employed a multiobjective GA model to perform optimization of the makespan and the total EC simultaneously for a shop floor level. It became clear that the utilized GA model is quite effective to assess the scheme selection and, thus lowering the makespan and the EC to the least-possible value. Lei et al. [12] presented a novel teaching-learning-based optimization model for energy-efficient scheduling in hybrid flow shops. The computational results showed that the teachers' teaching-learning-based optimization method is a competitive algorithm for the considered hybrid flow shop scheduling problem. Berral et al. [13] have proposed a framework, which provides an intelligent consolidation methodology using techniques such as turning on/off machines, power-aware consolidation algorithms, and machine learning techniques to cope with uncertain information while maximizing the performance. It was concluded that their presented approach is close to the optimal placement and operates more efficiently when the level of uncertainty increases. Luo et al. [14] presented a resource scheduling algorithm using cloud computing and based on the energy efficient optimization methods. The relationship among infrastructure components and energy consumption of the cloud computing environment was analyzed, and the matching of task types and component power adjustment methods was also performed. Results concluded that, for those of jobs, which have not fully utilized the hardware environment, using their presented approach can significantly decrease the energy consumption. Moon et al. [15] investigated the production and energy efficiency of the parallel machine scheduling problem by considering time-dependent and machine-dependent electricity cost for industrial applications through optimizing the weighted sum of two criteria: the minimization of the make-span of production and the minimization of timedependent electricity costs. A hybrid genetic algorithm was also suggested to demonstrate the system's performance in the simulation experiments. Scheduling as a way to investigate the increasing energy concerns in manufacturing enterprises was studied by Fang et al. [16]. In addition, a flow-shop scheduling problem with a limitation on the peak power consumption, in addition to the traditional time-based objectives was investigated. The mathematical programming and combinatorial approaches were used to address this scheduling problem, and the proposed approaches were tested with instances arising from the manufacturing of cast iron plates. Kim et al. [17] proposed a model for estimating the energy consumption of each virtual machine without a measurement hardware and based on in-processor events generated by the virtual machine. A virtual machine scheduling algorithm which can provide computing resources on the basis of the energy budget of each virtual machine was also proposed. The suggested schemes were considered in the virtualization system. It became evident that the suggested schemes estimate and provide energy consumption with errors of less than $5 \%$ of the total energy consumption. Tavakoli [18] studied effective progress scheduling and control methods particularly for construction projects. A schedule detailed enough for projects comprising any or all of the different types of highway construction was discussed for repetitive and consistent use. The sequence of the considered operations was arranged to estimate the typical sequence of operations on the projects. In addition, the characteristics, which provide better monitoring, communication, record keeping, and more importantly, the improved scheduling functions were studied. Menesi et al. [19] proposed a fast near-optimum solution to the multimode resource-constrained scheduling problem in largescale projects, with and without resource-leveling constraints. Constraint programming was applied as an advanced mathematical optimization method for the considered scheduling problem. The obtained results with two case studies from the literature were compared to assess and prove the effectiveness and accuracy of the constraint programming.

In order to acquire a better concept towards the frequently used optimization goals and methods, a brief review of the classification drivers concerning the latest research works was performed and then outlined in the Table 1. 
Table 1.

\begin{tabular}{|c|c|c|c|c|c|c|c|c|c|c|c|c|c|c|c|c|c|c|c|c|c|c|}
\hline \multirow[b]{2}{*}{ 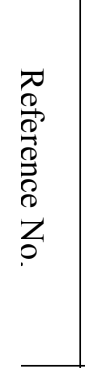 } & \multirow[b]{2}{*}{$\begin{array}{l}\vec{D} \\
\stackrel{\vec{E}}{0} \\
\stackrel{0}{w}\end{array}$} & \multirow[b]{2}{*}{$\underset{ه}{\overparen{g}}$} & \multicolumn{6}{|c|}{ Optimization model } & \multicolumn{14}{|c|}{ Optimization goal } \\
\hline & & & $\rho$ & ש & $\underset{\mho}{ٍ}$ & 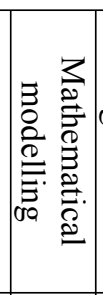 & 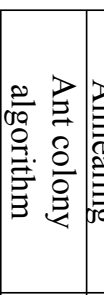 & 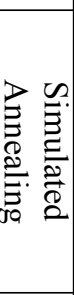 & 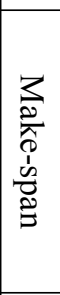 & 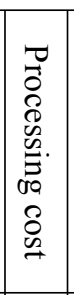 & 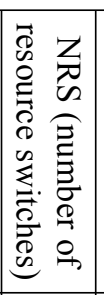 & 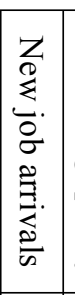 & 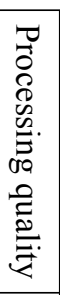 & 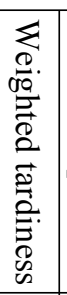 & 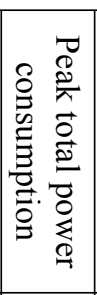 & 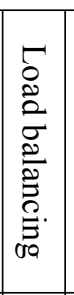 & 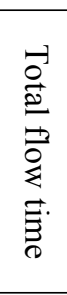 & 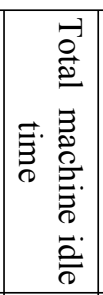 & त्ञ & 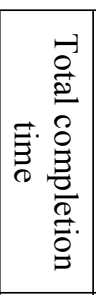 & 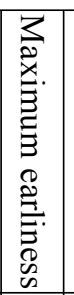 & 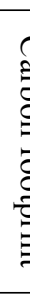 \\
\hline 1 & $\begin{array}{l}\text { Lee \& } \\
\text { Pinedo }\end{array}$ & $\begin{array}{c}199 \\
7\end{array}$ & & & $\mathrm{X}$ & & & $\mathrm{X}$ & $\mathrm{X}$ & & & & & $\mathrm{X}$ & & & & & & & & \\
\hline 2 & Damadaran & $\begin{array}{c}200 \\
4\end{array}$ & & & $\mathrm{X}$ & & & & $\mathrm{X}$ & & & & & & & & & & & & & \\
\hline 3 & Eren & $\begin{array}{c}200 \\
7\end{array}$ & & & $\mathrm{X}$ & & & & & & & & & $\mathrm{X}$ & & & & & & $X$ & & \\
\hline 4 & Mouz.. et al. & $\begin{array}{c}200 \\
7\end{array}$ & & & $\mathrm{X}$ & & & & $\mathrm{X}$ & & & & & & $\mathrm{X}$ & & & & & & & y \\
\hline 5 & Xiang \& Lee & $\begin{array}{c}200 \\
8\end{array}$ & & & & & $\mathrm{X}$ & & $\mathrm{X}$ & & & & & & & & $\mathrm{X}$ & $\mathrm{X}$ & & & & \\
\hline 6 & Ling-li & $\begin{array}{c}200 \\
9\end{array}$ & & $\mathrm{X}$ & & & & & & & & & & & & & & & $\mathrm{X}$ & & & \\
\hline 7 & Guerr.. et al. & $\begin{array}{c}201 \\
0\end{array}$ & $\mathrm{X}$ & $\mathrm{X}$ & & & & & & & & & & & & $X$ & & & & & & \\
\hline 8 & Wang et al. & $\begin{array}{c}201 \\
0\end{array}$ & & $X$ & & & & & $\mathrm{X}$ & & & $\mathrm{X}$ & & & & & & & & & & \\
\hline 9 & $\begin{array}{l}\text { Bruzzo.. et } \\
\text { al. }\end{array}$ & $\begin{array}{c}201 \\
2\end{array}$ & & & $\mathrm{X}$ & & & & & & & & & & & & & & $\mathrm{X}$ & & & \\
\hline 10 & Dai et al. & 201 & $\mathrm{X}$ & & & & & $\mathrm{X}$ & $\mathrm{X}$ & & & & & & & & & & $\mathrm{X}$ & & & \\
\hline
\end{tabular}

11 Obpiessd ainvestrgdting the literature review is indicative of $X$ the fact that the projects performed in this area of

12 morufacturing is ${ }^{2}$ still ax the early stage of development $X$ requiring further 4 attention of the scientists and the

13 resqarcherrs to $\mathrm{p}^{2} \mathrm{l}^{1}{ }_{\text {into }} \mathrm{X}^{\mathrm{effect}}$ strategic plans for more $X$ efficient design of batch processing machines. Several 4 researchers have 2010 concentrated on designing innovative $\mathrm{X}$ solutions to enhare the EC as well as the efficiency and

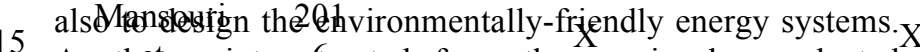
Anothet.. point extracted from the previously conducted researches $s_{1}$ was that, in the studies related to the flow shop $X$ 16 problems, the make-span, which is the total length of the schedule of a hybrid flow shop system has been considered as the primary objective of the optimization. As a matter of fact, minimizing the make-span plays a substantial role in enhancing the efficiency of a manufacturing system, since if future research were explained in the last section of the paper.

\section{MATERIAL AND METHODS}

\subsection{Definition of the primary optimization goals}

One objective function we are trying to optimize is considered to be make-span or maximum flow-time denoted with $C_{\max }$, which is the overall amount of time required for all the jobs in the batch to complete their processes in the machines. Make-span is also defined as the time difference between the starting, and finishing of a sequence of jobs or tasks. In a manufacturing company, the purpose of the optimization would be to minimize the maximum makespan in a considered range of jobs. the make-span is not decreased as much as pessible, the order of the products will not be shipped on time.

The remainder of the current research is stiuctured as follows: in the material and method section, the primary objective functions are specified. The problem \$tatement as well as the flowchart of the optimization process considering the sequencing methods was then Xescribed in the section 2.2. The scheduling parameters were also outlined in this section using a Gant chart flo $W_{V}$ diagram. Afterwards, the results and discussion are obtained in the third section, the make-span and EC considering each sequencing method was estimated and the variations of EC have also been studied. Finally, the conclusion of the results as well as the recommendations for

In addition to the make-span, minimizing the EC is also desirable not only for cost minimization purposes but also for environmental sustainability as well. The EC is considered as an important objective function during the analysis process. It primarily involves the amount of energy produced or consumed in a processing machine [3].

The third objective function is the total completion time. It is a point in time when machine has finished processing a job. It is an important criterion since the aim of many manufacturing companies in flow shop environments is to reduce the completion time of the processes as much as possible. 
also worthy to mention that, when the availability dates of a considered series of the job are zero, the shortest processing time would lead to minimization of the total completion time.

\subsection{Problem statement and development of the optimization model}

In the current research, three consecutive work stations for a manufacturing firm which function on the basis of a jobshop environment, each with two processing machines, and every operating machine consist of designated number of jobs have been considered for the analysis process. The flow-diagram of the analysis concerning the proposed and simulated job-shop environment depicting the schematic distribution of the jobs and parallel machines is shown in the Fig. 1. The considered data including job processing times (duration), completion time, starting and finishing time, along with the scheduling flow of tasks is depicted in the flow diagram in the Figs. 2, 3 and 4.

In the first step of the analysis, the scheduling variables including starting time, completion time, due date, and tardiness were defined. The preliminary objective functions such as optimum overall make-span, and tardiness were calculated. The sequencing of jobs was performed and the optimum energy consumption was obtained based on each sequencing rule. With the objective of determining the optimum completion time, in the second step of this study, a new approach according to the Pindedo's approach was proposed. For this purpose, the decision variables were classified into two main groups of input and output variables. The input variables include releasing date, processing time and the due date, whilst, the output variables consist of starting time, completion time and tardiness. Using several scheduling methods, the minimum completion time was obtained and compared for each of the machines.

Figure 1. The flow-diagram the three working stages for the parallel machines during the current analysis.

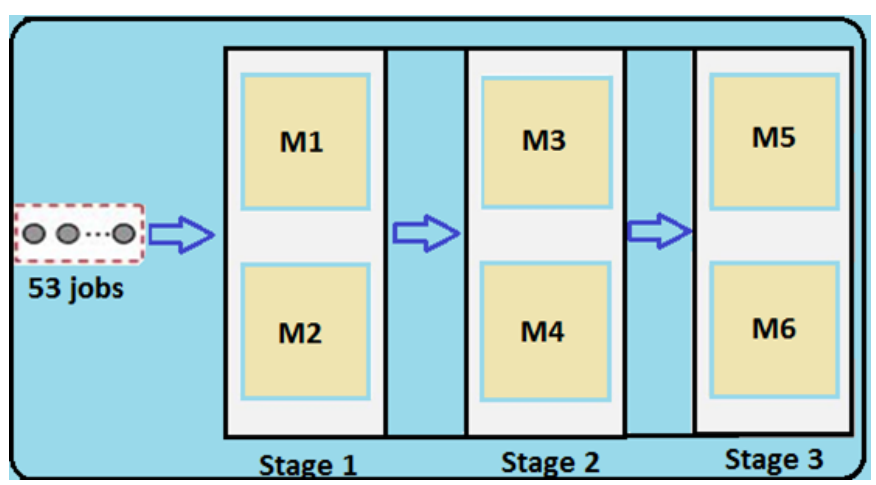

\begin{tabular}{|c|c|c|c|c|c|c|c|c|c|c|c|c|c|c|c|c|c|c|c|c|c|c|c|c|c|c|}
\hline \multirow{2}{*}{ ID } & \multirow{2}{*}{$\begin{array}{c}\text { Task } \\
\text { name }\end{array}$} & \multirow{2}{*}{ Starting time } & \multirow{2}{*}{ Finishing time } & \multirow{2}{*}{$c(t)(h)$} & \multirow{2}{*}{$\begin{array}{c}\text { Due date } \\
\text { (h) }\end{array}$} & \multirow{2}{*}{$\begin{array}{c}\text { Tardiness } \\
\text { (h) }\end{array}$} & \multirow{2}{*}{ Duration } & \multicolumn{19}{|c|}{ Oct 2016} \\
\hline & & & & & & & & 7 & 8 & 9 & \begin{tabular}{|l|l|}
10 & 1 \\
\end{tabular} & \begin{tabular}{l|l}
11 & 1 \\
1
\end{tabular} & \begin{tabular}{l|l}
12 & 13 \\
\end{tabular} & \begin{tabular}{|l|l|}
14 \\
\end{tabular} & 15 & 16 & 17 & \begin{tabular}{l|l|}
18 & 19 \\
\end{tabular} & \begin{tabular}{|l|l|}
20 & 21 \\
\end{tabular} & \begin{tabular}{l|l}
21 & 2 \\
\end{tabular} & \begin{tabular}{l|l}
22 & 23 \\
\end{tabular} & \begin{tabular}{|l|}
34 \\
\end{tabular} & \begin{tabular}{|l|l|}
25 & 26 \\
\end{tabular} & \begin{tabular}{l|l|l|}
26 & 27 & 28 \\
\end{tabular} & \begin{tabular}{|l|l|l|}
8 & 29 & 3 \\
\end{tabular} & \begin{tabular}{l|l}
30 & 31 \\
\end{tabular} \\
\hline 1 & M1 J1 & $10 / 7 / 2016$ & 10/10/2016 & 66 & 62 & 4 & $16 \mathrm{~h}$ & & & & & & & & & & & & & & & & & & & \\
\hline 2 & M1 J2 & 10/10/2016 & 10/14/2016 & 39 & 48.5 & 0 & $40 \mathrm{~h}$ & & & & 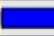 & & & & & & & & & & & & & & & \\
\hline 3 & M1 J3 & 10/14/2016 & 10/18/2016 & 30 & 20 & 10 & $17 \mathrm{~h}$ & & & & & & & E & & & & & & & & & & & & \\
\hline 4 & M1 J4 & 10/17/2016 & 10/18/2016 & 25 & 34.8 & 0 & $16 \mathrm{~h}$ & & & & & & & & & & & & & & & & & & & \\
\hline 5 & M1 J5 & 10/17/2016 & 10/20/2016 & 35 & 25.8 & 0 & $32 \mathrm{~h}$ & & & & & & & & & & & & 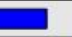 & & & & & & & \\
\hline 6 & M1 J6 & 10/21/2016 & 10/24/2016 & 40.8 & 35.8 & 9.2 & $12 \mathrm{~h}$ & & & & & & & & & & & & E & & & a & & & & \\
\hline 7 & M1 J7 & 10/25/2016 & 10/27/2016 & 50 & 42 & 8 & $20 \mathrm{~h}$ & & & & & & & & & & & & & & & & & ] & & \\
\hline 8 & M1 J8 & 10/27/2016 & 10/28/2016 & 19 & 19.2 & 0 & 10h & & & & & & & & & & & & & & & & & $\square$ & & \\
\hline 9 & \begin{tabular}{|l|} 
M1 J9 \\
\end{tabular} & 10/28/2016 & 10/31/2016 & 30 & 31 & 0 & $9 \mathrm{~h}$ & & & & & & & & & & & & & & & & & - & & 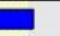 \\
\hline 10 & M1 J10 & 10/31/2016 & 10/31/2016 & 25 & 19 & 6 & $8 \mathrm{~h}$ & & & & & & & & & & & & & & & & & & & \\
\hline 11 & M2 J1 & 10/7/2016 & 10/10/2016 & 60 & 65 & 0 & $16 \mathrm{~h}$ & & & & 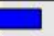 & & & & & & & & & & & & & & & \\
\hline 12 & M2 J2 & 10/10/2016 & 10/11/2016 & 40 & 42.2 & 0 & $16 \mathrm{~h}$ & & & & 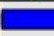 & 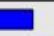 & & & & & & & & & & & & & & \\
\hline 13 & M2 J3 & 10/12/2016 & 10/14/2016 & 30 & 27 & 3 & $20 \mathrm{~h}$ & & & & & ᄃ & & $\square$ & & & & & & & & & & & & \\
\hline 14 & M2 J4 & 10/14/2016 & 10/18/2016 & 40 & 37 & 3 & $19 \mathrm{~h}$ & & & & & & & ⿷ & & 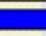 & 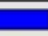 & & & & & & & & & \\
\hline 15 & M2 J5 & 10/17//2016 & 10/19/2016 & 32 & 30 & 2 & 18h & & & & & & & & & & 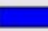 & & & & & & & & & \\
\hline 16 & M2 J6 & 10/17/2016 & 10/21/2016 & 36 & 35.8 & 0.2 & $36 \mathrm{~h}$ & & & & & & & & & & & & 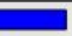 & & & & & & & \\
\hline 17 & M2 J7 & 10/20/2016 & 10/21/2016 & 38 & 35 & 3 & $12 \mathrm{~h}$ & & & & & & & & & & & & $\square$ & & & & & & & \\
\hline 18 & M2 J8 & 10/21/2016 & 10/25/2016 & 20.8 & 20 & 0.8 & $20 \mathrm{~h}$ & & & & & & & & & & & & - & $=$ & & & $\mathbf{a}$ & & & \\
\hline 19 & M2 J9 & 10/25/2016 & 10/28/2016 & 25.5 & 25 & 0.5 & $28 \mathrm{~h}$ & & & & & & & & & & & & & & & & E & & 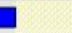 & \\
\hline 20 & M2 J10 & 10/28/2016 & 10/31/2016 & 22.2 & 22 & 0.2 & $16 \mathrm{~h}$ & & & & & & & & & & & & & & & & & & & \\
\hline
\end{tabular}

Figure 2. 


\begin{tabular}{|c|c|c|c|c|c|c|c|c|}
\hline \multirow{2}{*}{ ID } & \multirow{2}{*}{$\begin{array}{c}\text { Task } \\
\text { name }\end{array}$} & \multirow{2}{*}{ Starting time } & \multirow{2}{*}{ Finishing time } & \multicolumn{3}{|c|}{ C(t)/(t) Due date Tardiness } & \multirow{2}{*}{ Duration } & Oct 2016 \\
\hline & & & & $c(t)(h)$ & (h) & (h) & & 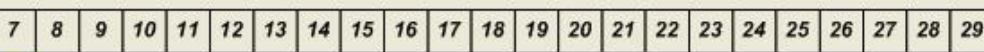 \\
\hline 1 & M3 J1 & 10/7/2016 & 10/7/2016 & 18 & 19 & 1 & $8 \mathrm{~h}$ & (1) \\
\hline 2 & M3 J2 & 10/9/2016 & 10/9/2016 & 16 & 19 & 3 & 8h & $\square$ \\
\hline 3 & м3 J3 & 10/11/2016 & 10/11/2016 & 16 & 16 & 0 & 8h & $\square$ \\
\hline 4 & M3 J4 & 10/12/2016 & 10/13/2016 & 22 & 25 & 3 & $9.5 \mathrm{~h}$ & 0 \\
\hline 5 & M3 J5 & 10/13/2016 & 10/14/2016 & 20 & 28 & 8 & $16 \mathrm{~h}$ & $\square$ \\
\hline 6 & M3 J6 & 10/14/2016 & 10/15/2016 & 25 & 30 & 5 & $16 \mathrm{~h}$ & 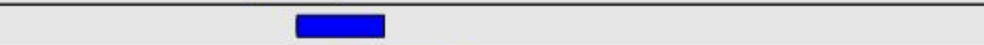 \\
\hline 7 & M3 J7 & 10/15/2016 & 10/17/2016 & 26 & 29 & 7 & $22 \mathrm{~h}$ & 工 \\
\hline 8 & M4 J1 & 10/18/2016 & 10/18/2016 & 12 & 12 & 0 & $6 \mathrm{~h}$ & $\square$ \\
\hline 9 & M4 J2 & 10/19/2016 & 10/20/2016 & 13 & 14 & 1 & 10h & $\square$ \\
\hline 10 & M4 J3 & 10/20/2016 & 10/21/2016 & 21 & 25 & 4 & $15 \mathrm{~h}$ & $\square$ \\
\hline 11 & M4 J4 & 10/20/2016 & 10/21/2016 & 22 & 29 & 7 & $14 \mathrm{~h}$ & 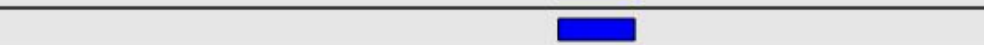 \\
\hline 12 & M4 J5 & 10/21/2016 & 10/22/2016 & 22 & 27 & 5 & $16 \mathrm{~h}$ & 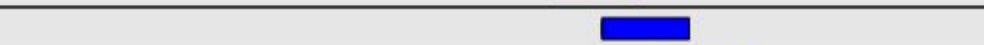 \\
\hline 13 & M4 J6 & 10/22/2016 & 10/24/2016 & 26 & 32 & 6 & $18 \mathrm{~h}$ & 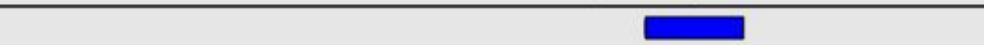 \\
\hline 14 & M4 J7 & 10/24/2016 & 10/25/2016 & 36 & 28 & 8 & $16 \mathrm{~h}$ & 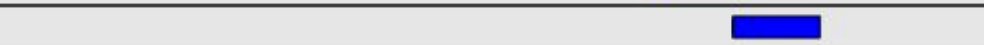 \\
\hline 15 & M4 J8 & 10/24/2016 & 10/25/2016 & 31 & 25 & 6 & $11.2 \mathrm{~h}$ & $\sigma$ \\
\hline 16 & M4 J9 & 10/25/2016 & 10/27/2016 & 40 & 31 & 9 & $24 \mathrm{~h}$ & 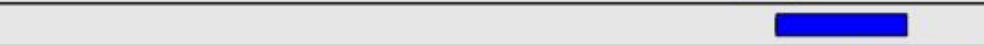 \\
\hline 17 & M4 J10 & 10/27/2016 & 10/29/2016 & 49 & 31 & 18 & $23 \mathrm{~h}$ & \\
\hline
\end{tabular}

Figure 3. The Gant chart flow-diagram demonstrating the scheduling parameters of the processed jobs in the stage 2 .

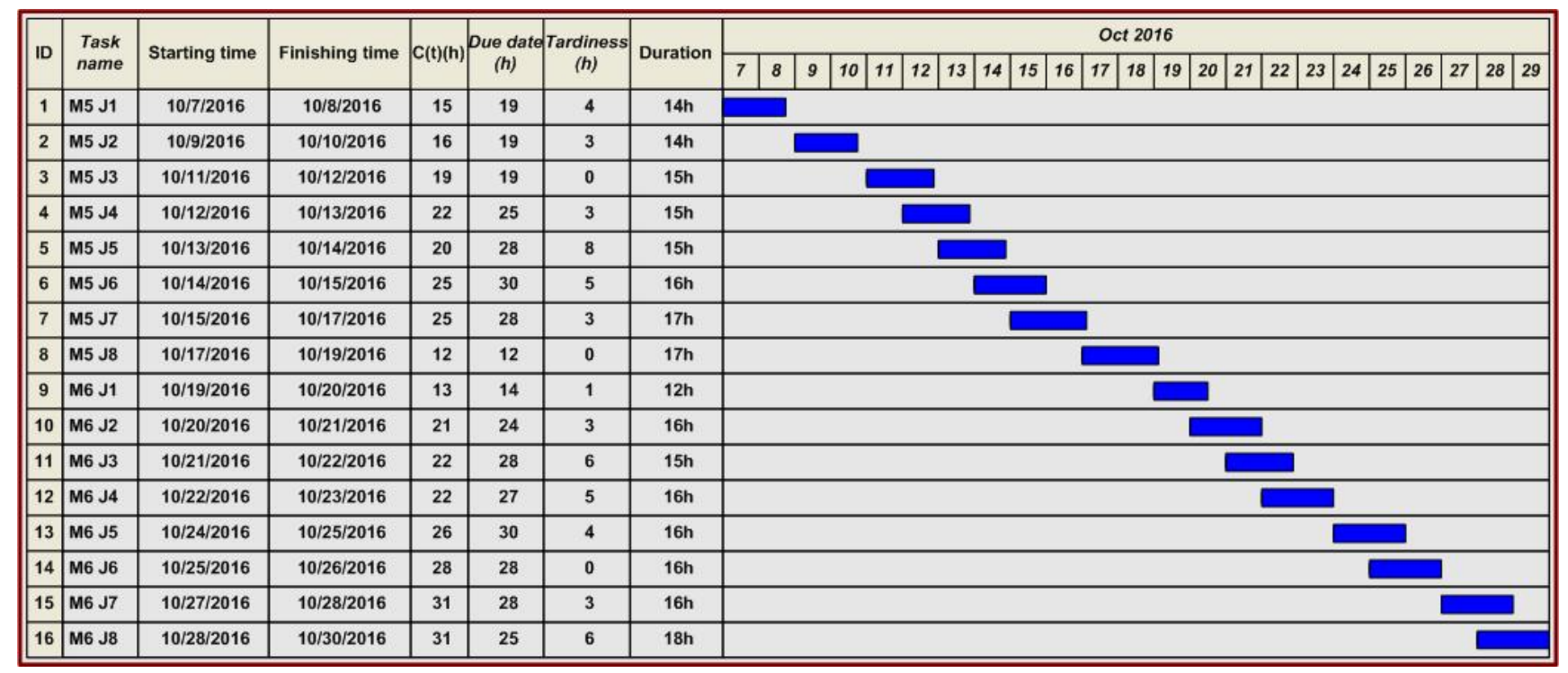

Figure 4. The Gant chart flow-diagram demonstrating the scheduling parameters of the processed jobs in the stage 3 .

\subsubsection{Description of the assumptions and constraints of the manufacturing system}

The manufacturing job-shop system has started operating from October $7^{\text {th }}, 2016,12: 00 \mathrm{pm}$ and finished its operation on October, $31^{\text {th }}, 7: 00 \mathrm{pm}$. The number of all operating machines were 6 processing machines, whilst the number of the jobs were 53. In addition, in the proposed job-shop is equipped with the two parallel machines in the first work station. The jobs coming to the job-shop environment, are processed by three consecutive work stations. Thus, the considered job-shop environment has three stages of development. Each stage, and working machines are independent of each other.

In order to measure the efficiency of the work station, allocation of the jobs was performed based on the assumption that two processing machines in the first work station are operating simultaneously nevertheless with different scheduling plans. Additionally, assigning the jobs is carried out with the purpose that all the studied jobs in the processing machines will have interfering hours and one short standby mode was applied during the operation of the first machine. However, in the second and third stages, the situation was quite different and although the work stations had numerous interfering hours, nevertheless, it was assumed that processing of the jobs would be in a consecutive manner. Two standby modes were considered during the operation of the first machine in the second stage, whilst no standby modes were applied in the third work station.

\subsection{Analysis of the sequencing of the jobs}

As a crucial stage during the scheduling process, the priority sequencing methods were employed to schedule more than one particular operation. Afterwards, each operation is then fulfilled in an independent manner. In the event that a considered work-station has idle hours, the priority rule is applied to those of jobs, which should be postponed for a particular operation, and a job, which has the highest priority is then selected. Subsequent to completing the operation process, a considered job is then moved forward to the next operation process in its routing. On this occasion, 37 
the job is waiting until it has the highest priority. With regard to each work-station, the jobs in the waiting line alter throughout a designated period of time, where they wait until they have the highest priority. Schedules are typically evaluated under different performance measures and variables.

In this study, in order to consider the effect of sequencing on the job-shop environment, based on the requirements of the proposed manufacturing company, four scenarios were considered during the analysis process, which are on the basis of FCFS (First come, first served), Johnson, SPT (Shortest processing time), and EDD (Earliest due date) methods. Fig. 5 demonstrates the flowchart of the proposed optimization model considering the sequencing methods, which are applied during the current scheduling analysis.

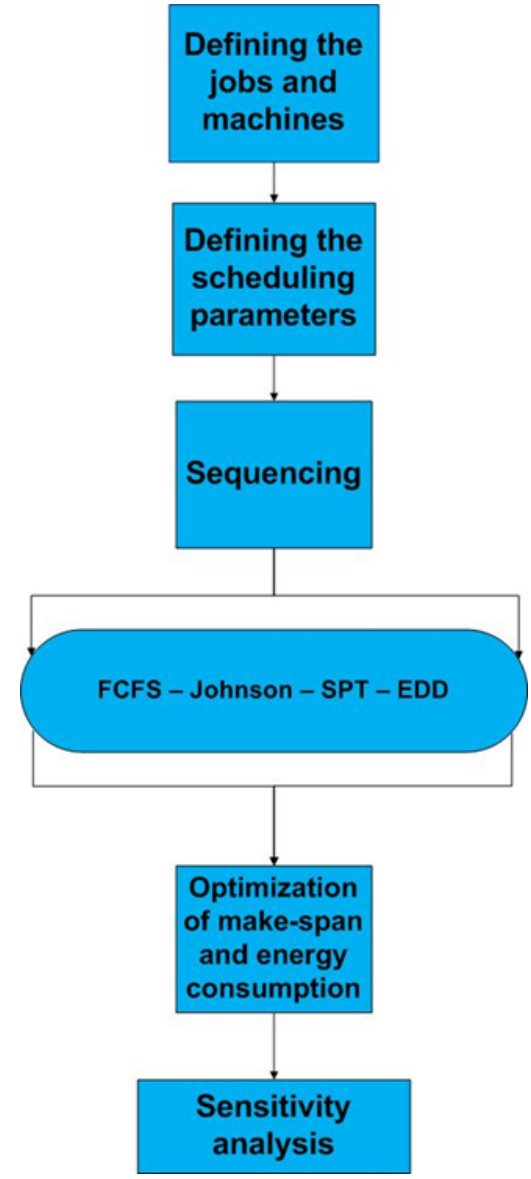

Figure 5. The schematic of the flow-diagram of the optimization process considering sequencing performed in the current analysis in the first step.

In the first scenario, which was performed using the FCFS method, the processing of the jobs coming to the job-shop environment on the basis of their order has been performed. The considered flow of the jobs for each work station is shown to be as follows:

Work station $_{1}: \mathrm{J}_{1}(16,16), \mathrm{J}_{2}(40,16), \mathrm{J}_{3}(17,20), \mathrm{J}_{4}(16$, $19), J_{5}(32,18), J_{6}(12,36), J_{7}(20,12), J_{8}(10,20), J_{9}(9$, 28), $\mathrm{J}_{10}(8,16)$.

Work station $_{2}: \mathrm{J}_{1}(8,6), \mathrm{J}_{2}(8,10), \mathrm{J}_{3}(8,15), \mathrm{J}_{4}(9.5,14)$, $\mathrm{J}_{5}(12,16), \mathrm{J}_{6}(16,18), \mathrm{J}_{7}(22,16), \mathrm{J}_{8}(0,11.2), \mathrm{J}_{9}(0,24)$, $\mathrm{J}_{10}(0,23)$.

Work station $_{3}$ : $\mathrm{J}_{1}(14,12), \mathrm{J}_{2}(14,16), \mathrm{J}_{3}(15,15), \mathrm{J}_{4}(15$, 16), $\mathrm{J}_{5}(15,16), \mathrm{J}_{6}(16,20.8), \mathrm{J}_{7}(17,16), \mathrm{J}_{8}(17,18)$
In the second scenario, an iterative process on the basis of the Johnson's method was developed and implemented to minimize the make-span for the proposed job-shop model. The general principle, which is based on trial and error is defined in a sense that the jobs with shortest processing times on the first operating machine come early in the sequence and jobs with short processing times on the second machine come later in the sequence [1]:

As a result, in order to determine the optimized make-span using this method, the new sequence for the first, second, and third work stations are considered to be as follows:

$$
\begin{aligned}
& J_{10}-J_{9}-J_{8}-J_{6}-J_{1}-J_{4}-J_{3}-J_{2}-J_{5}-J_{7} \\
& J_{2}-J_{3}-J_{4}-J_{5}-J_{7}-J_{6}-J_{10}-J_{9}-J_{8}-J_{1} \\
& J_{2}-J_{3}-J_{4}-J_{5}-J_{6}-J_{8}-J_{7}-J_{1}
\end{aligned}
$$

In the third scenario, the SPT method was considered, which aims to shorten the processing time of the jobs. With consideration of this rule, the sequencing begins with a designated job, which has the shortest processing time, and it ends with the job having the longest processing time. On this basis, the following arrangements were considered:

$$
\begin{aligned}
& \mathrm{SPT}_{11}: J_{10}-J_{9}-J_{8}-J_{6}-J_{4}-J_{1}-J_{3}-J_{7}-J_{5}-J_{2} \\
& \mathrm{SPT}_{12}: J_{7}-J_{10}-J_{2}-J_{1}-J_{5}-J_{4}-J_{8}-J_{3}-J_{9}-J_{6} \\
& \mathrm{SPT}_{23}: J_{1}-J_{2}-J_{3}-J_{4}-J_{5}-J_{6}-J_{7} \\
& \mathrm{SPT}_{24}: J_{1}-J_{2}-J_{8}-J_{4}-J_{3}-J_{5}-J_{7}-J_{6}-J_{10}-J_{9} \\
& \mathrm{SPT}_{35}: J_{1}-J_{2}-J_{3}-J_{4}-J_{5}-J_{6}-J_{7}-J_{8} \\
& \mathrm{SPT}_{36}: J_{1}-J_{3}-J_{2}-J_{4}-J_{5}-J_{6}-J_{7}-J_{8}
\end{aligned}
$$

It has been suggested that the EDD outperforms the SPT method, with respect to average past due, which is indicative of maintaining promises to the customers of a special product. Thereby, in this study, in the last scenario, taking into account the EDD method, the following arrangements concerning the first and second machines respectively were considered during the analysis process:

$$
\begin{aligned}
& \mathrm{EDD}_{11}: J_{10}-J_{8}-J_{3}-J_{5}-J_{9}-J_{4}-J_{6}-J_{7}-J_{2}-J_{1}(13) \\
& \operatorname{EDD}_{12}: J_{8}-J_{10}-J_{9}-J_{3}-J_{5}-J_{7}-J_{6}-J_{4}-J_{2}-J_{1}(14) \\
& \operatorname{EDD}_{23}: J_{3}-J_{1}-J_{2}-J_{4}-J_{5}-J_{7}-J_{6} \\
& \operatorname{EDD}_{24}: J_{1}-J_{2}-J_{3}-J_{8}-J_{5}-J_{7}-J_{4}-J_{9}-J_{10}-J_{6}(16) \\
& \operatorname{EDD}_{35}: J_{1}-J_{2}-J_{3}-J_{4}-J_{5}-J_{7}-J_{8}-J_{6} \\
& \operatorname{EDD}_{36}: J_{1}-J_{2}-J_{8}-J_{4}-J_{3}-J_{7}-J_{6}-J_{5}
\end{aligned}
$$

As can be seen from the sequencing analysis, Johnson model provides only one sequence for each work station, whilst the other models provide each sequencing for every machines in the work stations.

\subsection{Energy consumption analysis}

Energy utilization of the machines in a job-shop environment is perhaps one of the most important facets of the analysis, which have a tremendous effect on the reliability and efficiency of the job-shop. The EC of the machine, has been estimated based on the following equations [3]:

$$
\begin{aligned}
& E C[k W h]=\left\{C_{n}-C_{1}-\sum_{j=2}^{n} P_{j}\right\}[h] * I P[k W] * \\
& \sum_{j=1}^{n} Y_{j}[k W h]+P P \sum_{j=1}^{n} P_{j}[k W h] \\
& Y_{j}[k W h]=\left\{S E[k W]-\left(\left(C_{j+1}-P_{j+1}\right)-C_{j}\right)[h]\right\} I P[\mathrm{~kW}]
\end{aligned}
$$

Where EC is the mean value for the energy consumption $(\mathrm{kWh}), \mathrm{C}_{\mathrm{n}}$ is completion time for job $\mathrm{n}(\mathrm{h}), \mathrm{P}_{\mathrm{j}}$ is the processing time for job, $\mathrm{j}(\mathrm{h})$. IP is the Ideal Power $(\mathrm{kW}), \mathrm{Y}_{\mathrm{j}}$ 
is decision variable considering the energy for the setup, PP is the required power to process the job $(\mathrm{kW})$.

In addition, the following constraints were assumed for the considered operating machines:

$$
I P=12, \quad P P=13, \quad S E=20 ;
$$

\section{RESULTS AND DISCUSSION}

The analysis of this research has been performed according to the presented model described in the previous sections, and subsequently, the optimization results and flow diagram of the jobs and machines by taking into account the proposed sequencing methods, are achieved. The overall production make-span, which is independent of the sequencing algorithm, has been calculated to be $381,236.7$, and 248 hours for the first, second and third work stations respectively. Table 2 depicts the overall optimization results considering the internal and external decision variables.

It is also important bearing in mind that studying the variations of the EC of the machines and jobs play a substantial role in managing their energy requirements as well as the energy balancing over each jobs and machines. Table 3 demonstrates the estimated EC values for the studied machines using the proposed methods. Evidently, the sequencing process has resulted in lower EC values compared with the situation that no sequencing is applied during the operation of the machines.

The overall EC analysis concluded that the SPT method, in most occasions, results in more reduction of $\mathrm{EC}$ of the

\begin{tabular}{|c|c|c|c|c|c|}
\hline \multirow{2}{*}{ Stage } & \multirow{2}{*}{$\begin{array}{c}\text { Machine } \\
\text { number }\end{array}$} & $\begin{array}{c}\text { FCFS (First come, } \\
\text { first served) }\end{array}$ & Johnson & $\begin{array}{c}\text { SPT (Shortest } \\
\text { processing time) }\end{array}$ & $\begin{array}{c}\text { EDD (Earliest } \\
\text { due date) }\end{array}$ \\
\cline { 2 - 6 } & Machine 1 & 7,639 & 6,662 & 6,622 & 6491 \\
\hline \multirow{2}{*}{ Work station 1 } & Machine 2 & $8,168.5$ & 8,154 & $7,287.5$ & 9162.5 \\
\hline \multirow{2}{*}{ Work station 2 } & Machine 3 & $4,945.5$ & 4,997 & $6,137.7$ & 4991.5 \\
\cline { 2 - 6 } & Machine 4 & 5,916 & $6,541.8$ & 5,537 & 5909.8 \\
\hline \multirow{2}{*}{ Work station 3 } & Machine 5 & 6,363 & 6,398 & 6,096 & 6,364 \\
\cline { 2 - 6 } & Machine 6 & 6,294 & 6,714 & 6,304 & 6,306 \\
\hline
\end{tabular}

Table 2. The estimated EC values for the studied machines using the proposed methods.

In order to perform a more in-depth analysis on the EC of the investigated machines in the employed job-shop environment, the first work station was selected for the analysis and then the EC variations were reported in the Figs. 6 and 7. In the first situation, no assumptions for the sequencing process was considered. The minimum EC, was then calculated to be 476 and $670 \mathrm{kWh}$ for the first and second machines respectively. After applying the sequencing dispatching rules, the EC of the investigated machines has changed. In some occasions, the EC was increased, whilst, in other occasions, it was considerably decreased. The optimum EC for the first and second operating machines in the first work station was estimated to be 91 and $196 \mathrm{kWh}$ respectively. Looking through the graphical results, it is obvious that the work stations have experienced considerable fluctuations of EC during processing of the jobs and machines. Overall, it can be concluded that, there has been a significant reduction in the EC values, when the SPT method was employed. Another interesting finding of this research was that, obviously, once the processing of the initial jobs for the two machines was completed, considering the optimum sequencing method utilized in the first work station, a sudden reduction of EC machines than other methods. However, in a few cases, the FCFS and EDD have also been able to provide an adequate result of the optimization. The SPT method has achieved a sufficient result during the operation of the first workstation. It has also given adequate results for the fourth machine in the second work-station, and the fifth machine, in the third work station. By inspecting the results more precisely, it has become evident that, in the first workstation, which contains two parallel machines, the EC obtained by the SPT model is more efficient. Additionally, in the studied job-shop environment, the first machine operating on the basis of the SPT rule, the fourth machine operating on the basis of the FCFS rule, and finally, the fifth machine operating on the basis of the SPT rule have produced the least EC levels in each work station

Table 3. The overall optimization results of the objective functions.

\begin{tabular}{|c|c|c|c|}
\hline Stage & $\begin{array}{c}\text { Machine } \\
\text { type }\end{array}$ & $\begin{array}{l}\text { Overall Make- } \\
\text { span (h) }\end{array}$ & $\begin{array}{c}\text { Average } \\
\text { tardiness (h) }\end{array}$ \\
\hline \multirow{2}{*}{ Stage 1} & $\mathrm{M}_{1}$ & \multirow{2}{*}{381} & 37.2 \\
\hline & $\mathrm{M}_{2}$ & & 12.7 \\
\hline \multirow{2}{*}{ Stage 2} & $\mathrm{M}_{3}$ & \multirow{2}{*}{236.7} & 3.85 \\
\hline & $\mathrm{M}_{4}$ & & 6.4 \\
\hline \multirow{2}{*}{ Stage 3} & $\mathrm{M}_{5}$ & \multirow{2}{*}{248} & 3.25 \\
\hline & $\mathrm{M}_{6}$ & & 3.5 \\
\hline
\end{tabular}

for the second machine was observed, however, the first machine experienced an increase in the EC value. The situation, as can be seen from Fig. 6, it has been different when the FCFS is utilized. On this occasion, both two machines have experienced a sudden reduction after processing of the first job in the first work station.

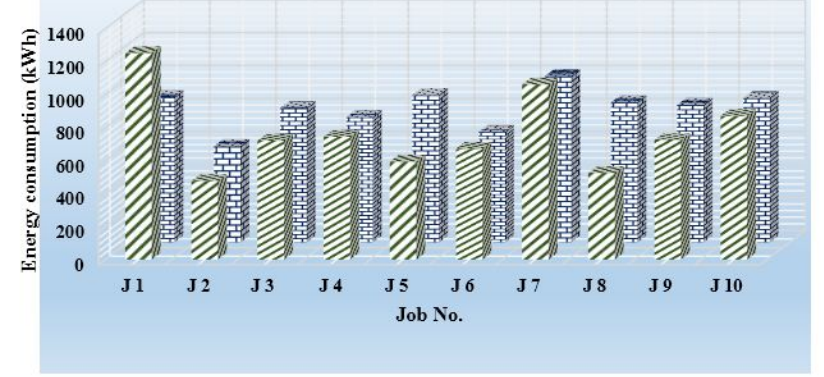

N Machine 1 ᄃMachine 2

Figure 6. The variations of the EC for the first work station with no sequencing. 
Overall results have also concluded that, in terms of the tardiness, machines 3,5 and 6 were among the best operating machines in the investigated work stations, which had the optimum average tardiness values. Additionally, it was also concluded that in terms of the make-span productivity, the first work station followed by the second one demonstrated a greater performance.

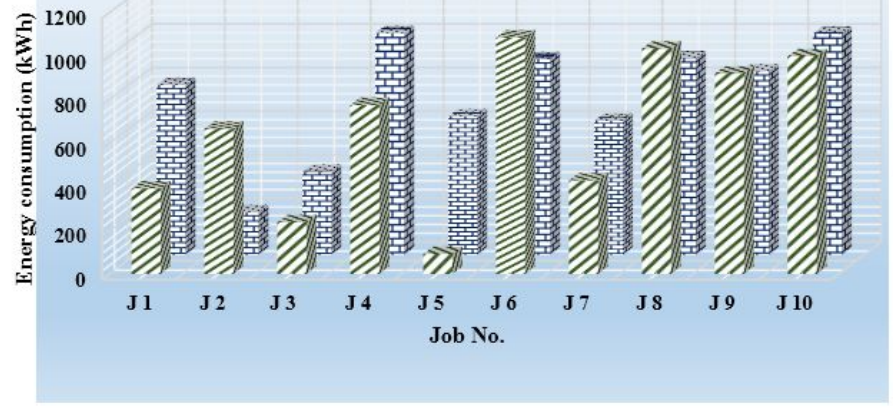

NMachine 1 +Machine 2

Figure 7. Optimum EC variations for the first work station under effect of the most efficient scenario considering the SPT method.

In the second step of the analysis, a new approach based on the Pinedo's model [1] was presented to perform scheduling and planning of the machines by considering the minimum completion time as the primary objective function.

The input variables of the system including releasing date, due date and processing time were defined according to the

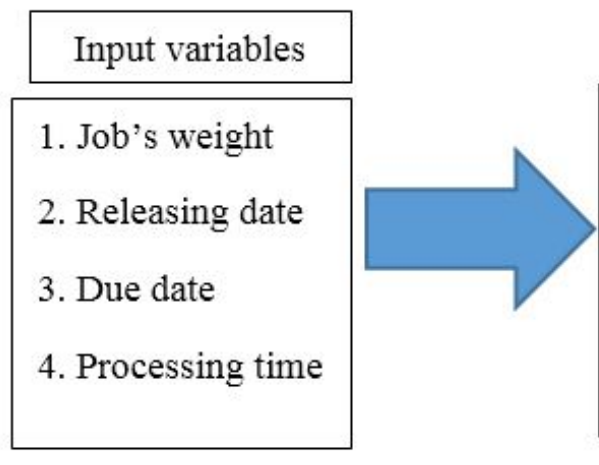

scheduling variables shown in the diagrams in the Figs. 2-4. The output variables, which consist of starting time, completion time and tardiness, were estimated. Fig. 8 shows the schematic flow of scheduling process of the decision variables for the considered job-shop manufacturing system.

For a given schedule, q, which is considered to be timeindependent, we have assumed that, $C_{i}=C_{i}(q)$ represent the completion time of job, $J_{i}$. The total completion time is denoted by $\sum_{i=1}^{n} C_{i}$. The objective function would therefore be defined as follows:

$$
\operatorname{Min} \frac{1}{n} \sum_{j \in J} C_{j}
$$

\begin{tabular}{|c|c|c|c|c|c|c|}
\hline \multirow{2}{*}{ Scheduling method } & \multicolumn{6}{|c|}{ Completion time values (h) } \\
\cline { 2 - 7 } & \multicolumn{2}{|c|}{$\mathrm{WS}_{1}$} & \multicolumn{2}{c|}{$\mathrm{WS}_{2}$} & \multicolumn{2}{c|}{$\mathrm{WS}_{3}$} \\
\cline { 2 - 7 } & $\mathrm{M}_{1}$ & $\mathrm{M}_{2}$ & $\mathrm{M}_{3}$ & $\mathrm{M}_{4}$ & $\mathrm{M}_{5}$ & $\mathrm{M}_{6}$ \\
\hline FCFS & 16 & 16 & 8 & 41 & 14 & 73 \\
\hline ATCSs & 24 & 19 & 8 & 18 & 14 & 26 \\
\hline EDD & 24 & 34 & 8 & 18 & 26 & 23 \\
\hline MS & 42 & 46 & 8 & 18 & 26 & 23 \\
\hline LPT (longest processing & 43 & 46 & 15 & 42 & 26 & 42 \\
\hline time) & & & & & & \\
\hline SPT & 16 & 16 & 8 & 18 & 14 & 26 \\
\hline WSPT & 16 & 16 & 8 & 18 & 14 & 26 \\
\hline CR & 42 & 34 & 12 & 18 & 26 & 23 \\
\hline
\end{tabular}

Table 3. The comparison of the least completion time values for each machines considering the proposed scheduling method.

Figure 8. The proposed schematic for the analysis of the decision variables

The Eq. (22) would determine a feasible schedule by which the average completion time or weighted completion time of the jobs is minimized. Table 4 depicts the estimated values for the minimum completion times of the studied machines according to each scheduling method.

Analysis of the completion time of the processed jobs shows that the least completion time values occurred at the second work station, $\mathrm{M}_{3}$ and it ranged from minimum of 8 to 15 hours. Clearly, this machine, compared with other processing machines, has less processing time values. There is also regular setup during the processing of the preliminary jobs. It is evident that for this machine, in most of the cases, we can assume: $P_{j+1}>P_{j}$. Such constraints have caused lowering the completion time of this machine significantly. 


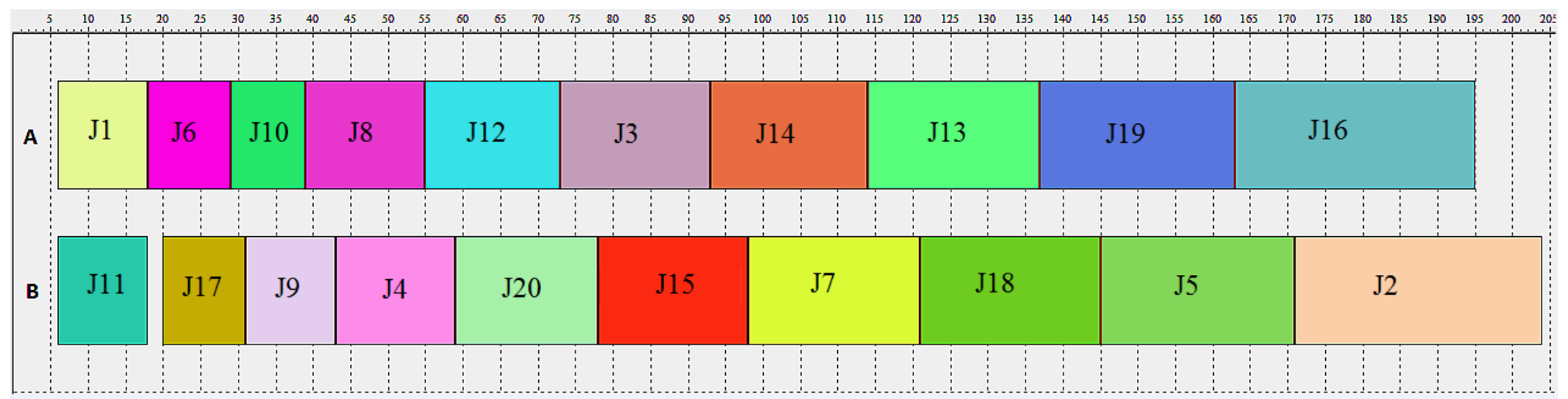

Figure 9. The optimum distribution of the jobs in the first work station under SPT rule.

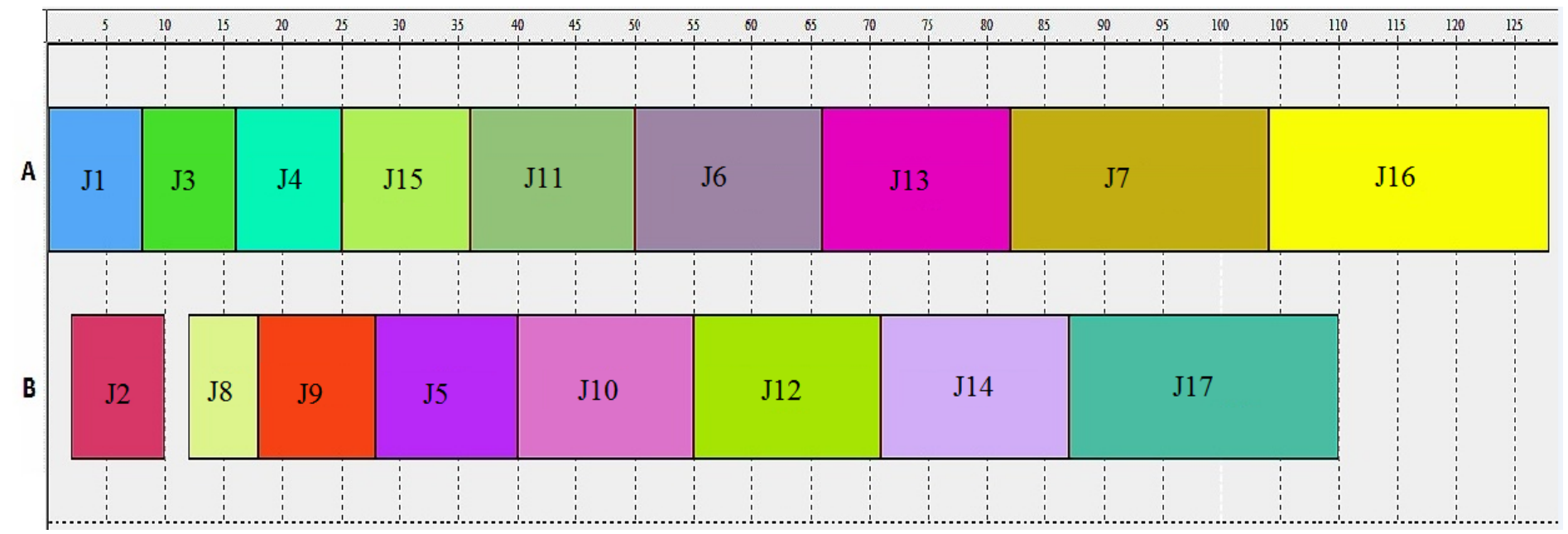

Figure 10. The optimum distribution of the jobs in the second work station under SPT rule.

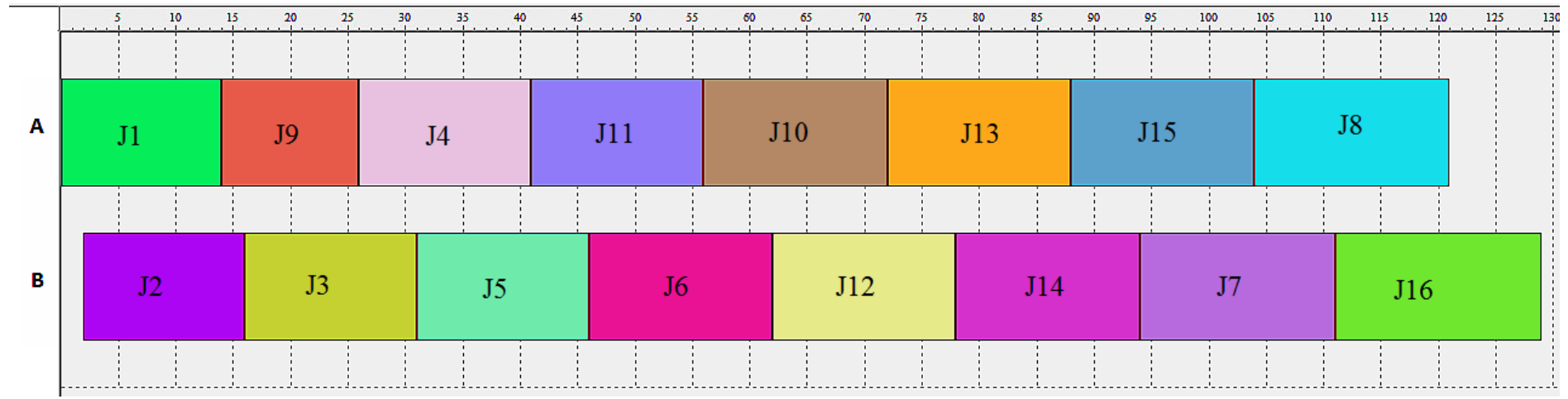

Figure 11. The optimum distribution of the jobs in the third work station under SPT rule.

On the other hand, machines 1 and 3, under effect of MS, CR and LPT in the case of first machine, and FCFS method in the case of third machine, have achieved considerably high values of completion time. It can be concluded that some scheduling methods have resulted in equal completion time for the studied work stations. In the first work station, the ATCSs (Apparent tardiness cost with setups), SPT and WSPT (weighted shortest processing time) have led to equal completion time of 16 hours. In the second work station, in addition to the aforementioned scheduling methods in the first work station, the EDD and MS were also the ones, which resulted in equal completion times with value of 18 hours. In the third work station, the EDD, MS, and CR resulted in equal completion times with values of 26 and 23 hours for the fifth and sixth machines respectively. In this work station, the completion times using the SPT and WSPT were calculated to be 14 and 26 for the fifth and sixth machines respectively. Overall, it can be concluded that among all scheduling methods, the SPT, WSPT, and ATCSs proved to be more effective in minimization of completion time of the jobs in the considered schedule. Given the fact that, in the energy analysis of the paper, the SPT method was also recommended for minimizing the energy consumption of machines, this method was therefore selected to design the optimum schedule of the jobs in terms of distribution of the jobs in the manufacturing system. Figs. $9-11$ demonstrate the new distribution of the jobs in the manufacturing system under effect of the SPT rule, which are classified into two groups.

The distribution of the jobs in the manufacturing system shows that there should be a setup in the second processing machine, (B), which operates in the first and second work stations of the manufacturing system. However, for the rest of machines, the setup is not recommended. As shown in the diagrams in the Figs. 9 - 11, the optimum make-span according to the SPT rule and Pinedo's approach are estimated to be 199,128 , and 129 hours in the event that the 
completion time is considered as the primary objective function.

\section{CONCLUSION}

In the current analysis, three consecutive work stations including 53 jobs are considered for the optimization and evaluation process from a technical viewpoint. The scheduling parameters are extracted from the considered manufacturing company and then the flow diagram of the distributed jobs over the studied machines taking into account four sequencing methods was proposed. The overall make-span was estimated to be $381 \mathrm{~h}, 236.7 \mathrm{~h}$, and $248 \mathrm{~h}$ for the first, second, and third work stations respectively. In addition, the variations of the EC amongst three work stations was also studied. It was concluded that the SPT model has been able to provide better results for the EC values. However, in a few cases, the FCFS and EDD have also been able to provide an adequate result of the optimization. The SPT method specifically has achieved a sufficient result during the operation of the first workstation. Analysis of the make-span as well as the EC showed that, there is a conflicting relation among these two characteristics during processing of first two work stations. However, during the operation of the third work station, whilst the make-span has been increasing, the EC was also increasing. Thus it can be recommended that, variations of the energy utilization of the machines together with the make-span depends on design and structure of the work stations in terms of the scheduling variables.

The completion time of the machines was also considered as another objective function of the job-shop environment. For this purpose, an approach based on the Pinedo's method was proposed to estimate the minimum the optimum schedule through minimizing the completion time of studied work stations. Due to different technical reasons of the job-shop environment, the least completion time values occurred in the third machine from the second work station, and it ranged from minimum of 8 to 15 hours. It also became clear that among all scheduling methods, the SPT, WSPT, and ATCSs proved to be more effective in minimization of completion time of the jobs in the considered schedule.

Obviously, the recent developments in supply chain management, internet technology, and the on-line transaction of buying or selling goods, have led to producing new but relatively complicated scheduling problems. These have received the attention of several researchers and scientists worldwide. Thereby, the necessity of amplifying the global research in the field of scheduling through covering these new and emerging problems can be clearly observed. Along with these avenues of research, outlining new industrial scheduling methods would certainly aid to solve the practical scheduling problems. Further research can therefore take into account an innovative bridge for the gap among the theoretical developments and industrial practices in production scheduling as well as the control methods.

\section{NOTATIONS LIST AND THEIR DESCRIPTION:}

$\mathrm{P}_{i j}$ : Processing time job $j$ at machine $i$

$r_{j}$ : release dating of job, $j$. $\mathrm{d}_{j}$ : Due date of job $j$.

$C_{11}$ : Completion time of first job on first machine.

$C_{n}$ : Completion time for the job, $\mathrm{n}$.

$Y_{j}$ : Decision variable considering the energy for the setup for the job, $j$.

$\mathrm{M}_{n}$ : Machine (number $\mathrm{n}$ ).

$\mathrm{WS}_{n}$ : Work station (number $\mathrm{n}$ ).

EC: Energy consumption.

MS: Minimum slack.

$\mathrm{SPT}_{\mathrm{WM}}$ : Shortest processing time for the work station $w$, and machine $m$.

$\mathrm{EDD}_{\mathrm{WM}}$ : Earliest due date for work station $w$ and machine $m$

\section{REFERENCES:}

1. Michael, L. (2008). Pinedo Scheduling: Theory, Algorithms, and System. Springer. ISBN 978-1-46142361-4

2. Johnson, S.M. (1954), "Optimal two and three-stage production schedules with set-up times included", Naval Research Logistics Quarterly, Vol. 1, pp. 61-68.

3. Mouzon, G., Yildirim, M. B., \& Twomey, J. (2007), "Operational methods for minimization of energy consumption of manufacturing equipment", International Journal of Production Research, Vol. 45 No. 18-19, pp. 4247-4271.

4. Fu, Y., Ding, J., Wang, H., \& Wang, J. (2018). Twoobjective stochastic flow-shop scheduling with deteriorating and learning effect in Industry 4.0-based manufacturing system. Applied Soft Computing, Vol. 68, pp. 847-855.

5. Wang, J., Li, J., \& Huang, N. (2011), “Optimal vehicle batching and sequencing to reduce energy consumption and atmospheric emissions in automotive paint shops", International Journal of Sustainable Manufacturing, Vol. 2 No. 2-3, pp. 141-160.

6. Fang, K., Uhan, N., Zhao, F., \& Sutherland, J. W. (2011), "A new shop scheduling approach in support of sustainable manufacturing", Glocalized solutions for sustainability in manufacturing, pp. 305-310.

7. Karasakal, E. K., \& Köksalan, M. (2000), “A simulated annealing approach to bicriteria scheduling problems on a single machine", Journal of Heuristics, Vol. 6, No. 3, pp. 311-327.

8. Xu, Z., Xu, D., He, J., Wang, Q., Liu, A., \& Xiao, J. (2018). Mixed Integer Programming Formulations for Two-Machine Flow Shop Scheduling with an Availability Constraint. Arabian Journal for Science and Engineering, 43(2), 777-788.

9. Wang, J., Li, J., \& Huang, N. (2011), “Optimal vehicle batching and sequencing to reduce energy consumption and atmospheric emissions in automotive paint shops", International Journal of Sustainable Manufacturing, Vol. 2 No. 2-3, pp. 141-160.

10. Guerrero, C. A., Wang, J., Li, J., Arinez, J., Biller, S., Huang, N., \& Xiao, G. (2011), "Production system design to achieve energy savings in an automotive paint shop", International Journal of Production Research, Vol. 49 No. 22, pp. 6769-6785. 
11. Yan, J., Li, L., Zhao, F., Zhang, F., \& Zhao, Q. (2016), "A multi-level optimization approach for energyefficient flexible flow shop scheduling", Journal of Cleaner Production, Vol. 137, pp. 1543-1552.

12. Lei, D., Gao, L., \& Zheng, Y. (2018). A novel teachinglearning-based optimization algorithm for energyefficient scheduling in hybrid flow shop. IEEE Transactions on Engineering Management, 65(2), 330340.

13. Berral, J. L., Goiri, Í., Nou, R., Julià, F., Guitart, J., Gavaldà, R., \& Torres, J. (2010, April). "Towards energy-aware scheduling in data centers using machine learning." Proceedings of the 1st International Conference on Energy-efficient Computing and Networking, New York, 215-224.

14. Luo, L., Wu, W., Di, D., Zhang, F., Yan, Y., \& Mao, Y. (2012, June). A resource scheduling algorithm of cloud computing based on energy efficient optimization methods. In Green Computing Conference (IGCC), 2012 International (pp. 1-6). IEEE.
15. Moon, J. Y., Shin, K., \& Park, J. (2013). Optimization of production scheduling with time-dependent and machine-dependent electricity cost for industrial energy efficiency. The International Journal of Advanced Manufacturing Technology, 68(1-4), 523-535.

16. Fang, K., Uhan, N. A., Zhao, F., \& Sutherland, J. W. (2013). Flow shop scheduling with peak power consumption constraints. Annals of Operations Research, 206(1), 115-145.

17. Kim, N., Cho, J., \& Seo, E. (2014). Energy-credit scheduler: an energy-aware virtual machine scheduler for cloud systems. Future Generation Computer Systems, 32, 128-137.

18. Tavakoli, A. (1990). Effective Progress Scheduling and Control for Construction Projects. Journal of Management in Engineering, 6(1), 87-98.

19. Menesi, W., \& Hegazy, T. (2014). Multimode resourceconstrained scheduling and leveling for practical-size projects. Journal of management in engineering, 31(6), 04014092 . 